\title{
Prevalence and Determinants of Over-the-Counter Analgesics Usage among Patients attending Primary Health Care Centers in Jeddah, Saudi Arabia
}

\author{
Shaza Dawood Babakor ${ }^{1}$, Majid Mohammed Al Ghamdi ${ }^{2}$ \\ 'Joint Program of Family Medicine, Family Medicine Resident, KINGDOM OF SAUDI ARABIA. \\ ${ }^{2}$ Consultant Community Medicine, Director of programme of community and preventive medicine, Ministry of Health, Jeddah, KINGDOM OF SAUDI ARABIA.
}

\begin{abstract}
Objective: To estimate the prevalence and describe the pattern of OTC use among patients attending primary healthcare (PHC) centers, and to assess their knowledge and attitude regarding the related side effects. Method: A cross-sectional study was carried out among 400 adult patients attending the General Medicine clinic in 10 selected PHC centers in Jeddah, Saudi Arabia. The data collected included socioeconomic parameters, practice and pattern of OTC analgesics use in past 6 months, knowledge and attitude about OTC analgesics, and safety assessment. Results: Results showed that $84.4 \%$ of the participants were using OTC analgesics, at least twice per week in $59.3 \%$ of the cases, and for $<1$ week duration in $65.8 \%$. The prevalence of use was highest among illiterate and highly educated participants $(p=0.000)$, and those with moderate income $(p=0.011)$. Acetaminophen (paracetamol) was the most frequently used drug $(86.1 \%)$, followed by ibuprofen $(25.1 \%)$ and diclofenac $(14.7 \%)$; and headache $(71.1 \%)$, arthralgia $(17.7 \%)$ and toothache $(17.4 \%)$ were the most common conditions leading to usage. A simple health problem $(64.0 \%)$, previous experience with the drug $(35.1 \%)$ and lack of time $(12.1 \%)$ were the most common reasons for OTC analgesics use. Among all, 58.1\% admitted having no knowledge about OTC analgesic side effects; while $7.1 \%$ reported having experienced side effects. Conclusion: There is an alarming prevalence of OTC analgesics use among patients, with inadequate
\end{abstract}

levels of awareness about the associated risks. Awareness and knowledge of users should be further investigated to determine the need for information for this specific or a larger population.

Key words: Analgesics, Auto medication, Non-steroid anti-inflammatory, Over-the-counter, Painkiller, Paracetamol.

\section{Key Message}

There is high prevalence of OTC analgesics usage combined with low levels of awareness and knowledge about the related hazards; which exposes to misusage that may carry accidents and severe side effects especially among the high-risk populations. The lack of awareness and knowledge highlights the need for targeted information.

\section{Correspondence:}

Shaza Babakor, Joint Program of Family Medicine, Family Medicine Resident, KINGDOM OF SAUDI ARABIA.

Phone: +966542785785

Email: dr.s.babaker@hotmail.com

DOI: 10.5530/jyp.2018.10.21

\section{INTRODUCTION}

Analgesics, including non-steroidal anti-inflammatory drugs (NSAIDs) and paracetamol (acetaminophen), are the most commonly used overthe-counter (OTC) drugs in the world..$^{1,2}$ Over-the-counter analgesics represent a convenient solution for self-care and are generally safe, if used in appropriate dosage. It is important to understand the determinants of the consumption of OTC analgesics, especially in high-risk population such as the elderly and individuals with comorbid conditions, as they are more vulnerable to eventual adverse events. ${ }^{3,4,5,6}$ Further, long-term consumption of OTC analgesics may result in severe adverse events, such as a loss of cognition, dehydration, depression, incontinence, poor quality of life and hospitalization. ${ }^{7}$ Approximately $25 \%$ of the patients taking NSAIDs face several adverse events, even in case of prescribed drug; and several cases of deaths are reported in relation with acetaminophen overdoses. ${ }^{8,9}$ On the other hand, OCT analgesics are generally perceived as non-harmful by the population; and consequently, many users end up with misuse.

In the developed countries, sale, purchase and consumption of OTC analgesics are strictly regulated since 1998 . However, there is still a need to develop a comprehensive strategy to educate people and make effective legislations to prevent the misuse of OTC analgesics and the associated risks. ${ }^{10}$ It is important to increase awareness and knowledge about OTC analgesics usage and their possible side effects and to screen and prevent risky behaviors and attitudes among users. In Saudi Arabia, several studies investigated the usage of OTC analgesics, either directly or indirectly by exploring self-medication or OTC drugs used in general. A range of objectives has been explored including perception, practice and patterns of usage; but data are still scarce to estimate the need for information among the local population. Thus, such studies are useful to highlight the extent of the risks related to OTC drug use among the population and clarify the role of physicians to educate patients about the potential side effects of OTC analgesics and to keep an adequate level of medical vigilance. In addition, conducting such studies may unveil the gaps in health legislations related to dispensation of OTC analgesics.

The present study aims to provide an insight into the extent of OTC analgesics use and to improve awareness and knowledge about the related health risks among patients visiting primary healthcare ( $\mathrm{PHC})$ centers in the Western Province of Saudi Arabia.

\section{MATERIALS AND METHODS}

A cross-sectional study conducted between 1-30 of March 2016, at selected PHC centers in Jeddah, Saudi Arabia. This study involved adult patients (age $>15$ years) of both genders visiting the General Medicine clinic in 
the participating centers during the study period; while patients visiting other clinics or mentally disabled patients were excluded. The target sample size was calculated to detect an expected $55.4 \%$ prevalence of OTC analgesics use, ${ }^{11}$ with $5 \%$ margin error and $80 \%$ statistical power, among a total population of 70.994 in Jeddah PHCs (source: Public Health Administration). Calculated sample size was $\mathrm{N}=380$; which was increased to 400 to compensate for probable dropouts.

Jeddah is divided into 5 supervisory areas including Northern, Western, Eastern, Southern and Centre; each having distinct socioeconomic characteristics and is covered by 6-10 PHCs. A multi-stage stratified sampling technique was used to include eligible participants. In Stage 1, 2 PHC centers were selected from each supervisory area (stratum) using simple random sampling, which gave a total 10 PHC selected centers. In Stage 2, a systematic random sampling (every third patient) was used to include 40 eligible participants from each of the selected PHCs.

A semi-structured questionnaire was translated in Arabic language and administered by the researcher during a face-to-face interview. Face and content validity of the translated version (Arabic) was reviewed by two Family Medicine consultants. The questionnaire was divided into 4 parts as follows: Part 1: sociodemographic and economic data such as age, marital status, educational level, etc.; Part 2: practice and pattern of OTC analgesics use including usage during the past 6 months, frequency and duration of the use, type of drug used (paracetamol, NSAIDs [diclofenac, ibuprofen], or other), health condition leading to usage such as headache, fever, joint pain, etc., pain intensity urging to use (VAS pain score: 0 to 10), supply source such as pharmacy, home stock, supermarket, etc., and reasons for use OTC instead of prescribed analgesics such as minor health problem, lack of time or transport, etc; Part 3: knowledge and attitude about OTC analgesics, including knowledge source (family, pharmacist, media, etc.), practice in reading treatment leaflets, awareness about side effects related to OTC analgesics use, misuse and overdose (hepatotoxicity, nephrotoxicity, gastrointestinal disorders, etc.), and practice in case of inefficacy of the OTC analgesics in reducing pain (visit doctor, stop taking the treatment, continue treatment, etc.); Part 4: safety related to OTC analgesics use including history and type of side effects experienced (nausea and vomiting, stomach ache, rash, etc.), practice in case of side effects (consult doctor, reduce treatment dose, shift to another drug, etc.). The questionnaire was filled by the participants under investigator's supervision.

A pilot study was carried out on a sample of $10 \%$ of the total sample size $(\mathrm{N}=40)$ to assess validity, clarity and feasibility of the questionnaire Participants included in the pilot study were excluded from the study.

Both the study protocol and questionnaire were approved by the joint program of family and community medicine and public health administration, represented by the Department of Medical Research and Studies, Directorate of Health Affairs, Jeddah, Ministry of Health. Confidentiality was assured by anonymous data collection and coding of collected data in the database. Verbal consent was obtained from all the participants.

\section{Statistical Analysis}

Statistical analysis was carried out using SPSS, version 21 (IBM SPSS Statistics for Windows, Armonk, NY: IBM Corp. 2012). Descriptive statistics were used to analyze participants' sociodemographic characteristics, calculate the prevalence and 95\% confidence interval (CI) of OTC analgesics use, and describe the patterns of use. Continuous data were presented as mean \pm standard deviation (SD) and categorical data as frequency (percentages). Factors associated with OTC analgesics use were analyzed by comparing users with nonusers using chi-square test for categorical variables and independent $t$-test for continuous variables. Pattern of OTC use as well as knowledge and attitude were compared by gender, educational level and family income using chi-square test. A p-value $<0.05$ was considered for statistical significance.

\section{RESULTS}

\section{Sociodemographic Characteristics of the Study Population}

A total of 400 patients attending PHC centers were included (50.3\% were females; mean \pm SD age $=35.23 \pm 11.14$ years). Majority of the participants were married (76.8\%), living in Jeddah (96.5\%) and having low (42.0\%) or very low (20.0\%) family income. Professional status indicated a relatively high proportion of unemployed (45.5\%) participants, whereas $39.4 \%$ were highly educated (university+) (Table 1).

\section{Prevalence and the Pattern of OTC Analgesics Use}

The prevalence $(95 \% \mathrm{CI})$ of OTC analgesics use was $84.8 \%(80.8 \%$; $88.1 \%)$. The most frequently used drug was acetaminophen (86.1\%), followed by ibuprofen (25.1\%) and diclofenac (14.7\%). Majority of users (67.6\%) declared to purchase OTC analgesics at the pharmacy, $45.1 \%$ admitted having a personal stock at home, and $4.1 \%$ purchased it from the supermarket. Regarding the frequency of use, 59.3\% took OTC analgesics at least twice during the past 6 months, for less than a week duration in $65.8 \%$ of the cases (Table 2). The most frequent health condition motivating the use of OTC analgesic was headache $(71.1 \%)$, followed by arthralgia (17.7\%) and toothache (17.4\%) (Figure 1). Of all

\begin{tabular}{|c|c|c|c|}
\hline Parameter & Category & Frequency & Percentage \\
\hline \multirow[t]{2}{*}{ Gender } & Male & 199 & 49.8 \\
\hline & Female & 201 & 50.3 \\
\hline Age (years) & Mean, SD; $[$ range $=16 ; 64]$ & 35.23 & 11.14 \\
\hline \multirow[t]{2}{*}{ Nationality } & Saudi & 267 & 66.8 \\
\hline & Non-Saudi & 132 & 33.0 \\
\hline \multirow[t]{4}{*}{ Marital Status } & Married & 307 & 76.8 \\
\hline & Single & 79 & 19.8 \\
\hline & Divorced & 8 & 2.0 \\
\hline & Widowed & 6 & 1.5 \\
\hline \multirow[t]{8}{*}{ Educational Level } & Illiterate & 15 & 3.8 \\
\hline & Writes and reads & 17 & 4.3 \\
\hline & Primary & 31 & 7.8 \\
\hline & Middle school & 38 & 9.5 \\
\hline & Secondary & 136 & 34.0 \\
\hline & Diploma & 23 & 5.8 \\
\hline & University degree & 129 & 32.3 \\
\hline & High studies & 5 & 1.3 \\
\hline \multirow[t]{2}{*}{ Residency } & Jeddah & 386 & 96.5 \\
\hline & Outside Jeddah & 9 & 2.3 \\
\hline \multirow[t]{4}{*}{ Career } & Unemployed & 182 & 45.5 \\
\hline & Retired & 17 & 4.3 \\
\hline & Student & 37 & 9.3 \\
\hline & Employed & 159 & 39.8 \\
\hline \multirow{4}{*}{$\begin{array}{l}\text { Family income } \\
\text { (SAR) }\end{array}$} & Up to $3 \mathrm{~K}$ & 80 & 20.0 \\
\hline & $>3 \mathrm{~K}-5 \mathrm{~K}$ & 168 & 42.0 \\
\hline & $>5 \mathrm{~K}-10 \mathrm{~K}$ & 106 & 26.5 \\
\hline & $>10 \mathrm{~K}$ & 41 & 10.3 \\
\hline
\end{tabular}




\begin{tabular}{|c|c|c|c|}
\hline Parameter & Category & Frequency & Percentage \\
\hline \multirow[t]{2}{*}{ OTC Analgesics use } & Yes & 339 & 84.8 \\
\hline & No & 61 & 15.3 \\
\hline \multirow[t]{9}{*}{ Treatment used } & Paracetamol & 292 & 86.1 \\
\hline & Ibuprofen & 85 & 25.1 \\
\hline & Diclofenac & 50 & 14.7 \\
\hline & Solpadeine (paracetamol + codeine + caffeine $)$ & 8 & 2.4 \\
\hline & Other & 4 & 1.2 \\
\hline & Panadol extra (Paracetamol + caffeine) & 1 & 0.3 \\
\hline & Lyrica & 1 & 0.3 \\
\hline & Buscopan (Butylscopolamine) & 1 & 0.3 \\
\hline & Ralpidos & 1 & 0.3 \\
\hline \multirow[t]{5}{*}{ Supply source } & Pharmacy & 229 & 67.6 \\
\hline & At home & 153 & 45.1 \\
\hline & Family \& friends & 3 & 0.9 \\
\hline & Supermarket & 14 & 4.1 \\
\hline & Primary healthcare center & 4 & 1.2 \\
\hline \multirow{5}{*}{$\begin{array}{l}\text { Frequency of use during the last } \\
6 \text { months }\end{array}$} & Once & 62 & 15.5 \\
\hline & Twice & 78 & 19.5 \\
\hline & 3 times & 57 & 14.3 \\
\hline & $>3$ times & 102 & 25.5 \\
\hline & Do not remember & 40 & 10.0 \\
\hline \multirow[t]{3}{*}{ Average duration of use } & $<1$ week & 263 & 65.8 \\
\hline & 1 week & 44 & 11.0 \\
\hline & $>1$ week & 30 & 7.5 \\
\hline \multirow[t]{7}{*}{ Chronic disease } & No & 270 & 79.6 \\
\hline & Yes & 69 & 20.4 \\
\hline & Hypertension & 28 & 8.3 \\
\hline & Diabetes & 27 & 8.0 \\
\hline & Asthma & 9 & 2.7 \\
\hline & Dyslipidemia & 5 & 1.5 \\
\hline & Other 1 & 13 & 3.8 \\
\hline Pain intensity (VAS) & Mean, SD & 6.50 & 2.52 \\
\hline \multirow[t]{3}{*}{ Pain intensity } & Mild (0-3) & 40 & 11.8 \\
\hline & Moderate (4-6) & 127 & 37.5 \\
\hline & Severe $(7+)$ & 169 & 49.9 \\
\hline
\end{tabular}

participants, $11.8 \%$ admitted using OTC analgesics for mild pain intensity (VAS pain score $0-3$ ), 37.5\% for moderate pain intensity (VAS score 4-6) and $49.9 \%$ for severe pain (VAS score $7+$ ) (Table 2).

\section{Knowledge and Attitude towards OTC Use and safety}

Among OTC analgesics users, $45.1 \%$ declared having self-gained knowledge about the drugs they use, $24.8 \%$ acquired knowledge about OTC analgesics from family, $16.5 \%$ from previous prescriptions, and $13.0 \%$ from the pharmacist; and $44.0 \%$ declared to read the drug information pamphlet (Table 3). Regarding circumstances or reasons for OTC use, simple health problem was invoked by majority of the users $(64.0 \%)$, followed by previous experience with the drug (35.1\%) and lack of time (12.1\%) (Figure 2). In case of inefficacy of the OTC analgesic, $64.6 \%$ declared to consult the doctor, $8.3 \%$ to stop the treatment, and $6.2 \%$ to shift to another treatment (Table 3).

Of the users, $58.1 \%$ admitted having no knowledge about OTC analgesic side effects; while $26.5 \%, 13.6 \%$ and $6.8 \%$ declared being aware of the risk of nephrotoxicity, hepatotoxicity and rash, respectively. Side effects subsequent to OTC analgesic use were reported by $7.1 \%$ of the users; with nausea or vomiting (2.7\%), rash (2.7\%) and stomachache (1.5\%) being the most frequent ones. In case of side effect, $3.8 \%$ declared consulting a doctor and $3.8 \%$ would stop the treatment immediately (Table 3 ). 


\begin{tabular}{|c|c|c|c|}
\hline Parameter & Category & Frequency & Percentage \\
\hline \multirow{7}{*}{ Knowledge source about OTC analgesics } & Personal knowledge & 153 & 45.1 \\
\hline & Family & 84 & 24.8 \\
\hline & Previous prescription & 56 & 16.5 \\
\hline & Pharmacist & 52 & 13.0 \\
\hline & Friends & 20 & 5.9 \\
\hline & Media & 15 & 4.4 \\
\hline & Other & 3 & 0.8 \\
\hline \multirow[t]{2}{*}{ Reading treatment brochure } & Yes & 149 & 44.0 \\
\hline & No & 190 & 56.0 \\
\hline \multirow[t]{2}{*}{ information provided by pharmacist } & Yes & 100 & 25.0 \\
\hline & No & 239 & 59.8 \\
\hline \multirow[t]{8}{*}{ Reasons for OTC analgesics use } & Simple health problem & 217 & 64.0 \\
\hline & Shortage of transport to care service & 35 & 10.5 \\
\hline & Lack of time to visit doctor & 41 & 12.1 \\
\hline & Friend's advice & 13 & 3.8 \\
\hline & High expense of doctor visit & 12 & 3.5 \\
\hline & Easy access to treatment & 32 & 9.4 \\
\hline & Serious condition & 4 & 1.2 \\
\hline & Treatment already used in the past & 119 & 35.1 \\
\hline \multirow[t]{7}{*}{ Attitude if OTC analgesic does not relieve pain symptoms } & This never happened & 49 & 14.5 \\
\hline & Consult doctor & 219 & 64.6 \\
\hline & Stop the OCT analgesic & 28 & 8.3 \\
\hline & Continue OCT analgesic & 19 & 5.6 \\
\hline & Shift to another treatment & 21 & 6.2 \\
\hline & Associate another treatment & 6 & 1.8 \\
\hline & Increase the dose & 1 & 0.3 \\
\hline \multirow[t]{2}{*}{ Self-reported Knowledge about OTC analgesics side effects } & Yes & 142 & 41.9 \\
\hline & No & 197 & 58.1 \\
\hline \multirow[t]{5}{*}{ Knowledge of specific side effects } & Nephrotoxicity & 90 & 26.5 \\
\hline & Hepatotoxicity & 46 & 13.6 \\
\hline & Rash & 23 & 6.8 \\
\hline & Abdominal discomfort & 21 & 6.2 \\
\hline & Cardiac toxicity & 21 & 6.2 \\
\hline \multirow[t]{3}{*}{ History of side effect on OCT analgesics } & Yes & 24 & 7.1 \\
\hline & No & 310 & 91.4 \\
\hline & Not sure & 5 & 1.5 \\
\hline \multirow[t]{11}{*}{ Patient-reported specific side effects } & Nausea andvomiting & 9 & 2.7 \\
\hline & Rash & 9 & 2.7 \\
\hline & Stomach ache & 5 & 1.5 \\
\hline & Stomach ulcer & 3 & 0.9 \\
\hline & Dyspnea & 3 & 0.9 \\
\hline & Headache & 3 & 0.9 \\
\hline & Diarrhea & 1 & 0.3 \\
\hline & Constipation & 1 & 0.3 \\
\hline & Vertigo & 1 & 0.3 \\
\hline & Jaundice & 1 & 0.3 \\
\hline & Others (elevation in BP, insomnia, renal colic) & 3 & 0.9 \\
\hline \multirow[t]{6}{*}{ Attitude regarding OTC analgesics side effects } & Visit doctor & 13 & 3.8 \\
\hline & Stop treatment & 13 & 3.8 \\
\hline & Switch to another treatment & 3 & 0.9 \\
\hline & Reduce dose & 2 & 0.6 \\
\hline & $\begin{array}{l}\text { Continue OTC and associate another treatment to } \\
\text { treat symptoms }\end{array}$ & 1 & 0.3 \\
\hline & Hospital admission & 1 & 0.3 \\
\hline
\end{tabular}




\begin{tabular}{|c|c|c|c|c|c|c|}
\hline \multirow[t]{3}{*}{ Parameter } & \multirow{3}{*}{ Category } & \multicolumn{4}{|c|}{ OTC analgesics use } & \multirow{3}{*}{$p$-value } \\
\hline & & \multicolumn{2}{|c|}{ Yes } & \multicolumn{2}{|c|}{ No } & \\
\hline & & Freq. & $\%$ & Freq. & $\%$ & \\
\hline \multirow[t]{2}{*}{ Gender } & Male & 166 & 83.4 & 33 & 16.6 & \multirow{2}{*}{.461} \\
\hline & Female & 173 & 86.1 & 28 & 13.9 & \\
\hline Age (years) & Mean, SD & 35.05 & 11.08 & 36.21 & 11.55 & .455 \\
\hline \multirow[t]{2}{*}{ Nationality } & Saudi & 240 & 89.9 & 27 & 10.1 & \multirow{2}{*}{$.000^{*}$} \\
\hline & Non-Saudi & 99 & 75.0 & 33 & 25.0 & \\
\hline \multirow[t]{4}{*}{ Marital Status } & Married & 258 & 84.0 & 49 & 16.0 & \multirow{4}{*}{.280} \\
\hline & Single & 71 & 89.9 & 8 & 10.1 & \\
\hline & Divorced & 6 & 75.0 & 2 & 25.0 & \\
\hline & Widowed & 4 & 66.7 & 2 & 33.3 & \\
\hline \multirow[t]{8}{*}{ Educational Level } & Illiterate & 14 & 93.3 & 1 & 6.7 & \multirow{8}{*}{$.000^{*}$} \\
\hline & Writes and reads & 11 & 64.7 & 6 & 35.3 & \\
\hline & Primary & 24 & 77.4 & 7 & 22.6 & \\
\hline & Middle school & 28 & 73.7 & 10 & 26.3 & \\
\hline & Secondary & 108 & 79.4 & 28 & 20.6 & \\
\hline & Diploma & 23 & 100.0 & 0 & 0.0 & \\
\hline & University degree & 121 & 93.8 & 8 & 6.2 & \\
\hline & High studies & 4 & 80.0 & 1 & 20.0 & \\
\hline \multirow[t]{5}{*}{ Educational level (5 categories) } & Illiterate & 14 & 93.3 & 1 & 6.7 & \multirow{5}{*}{$.000^{*}$} \\
\hline & Write and reads & 11 & 64.7 & 6 & 35.3 & \\
\hline & Primary - middle school & 52 & 75.4 & 17 & 24.6 & \\
\hline & Secondary & 108 & 79.4 & 28 & 20.6 & \\
\hline & University + & 148 & 94.3 & 9 & 5.7 & \\
\hline \multirow[t]{2}{*}{ Residency } & Jeddah & 326 & 84.5 & 60 & 15.5 & \multirow{2}{*}{$.366 \mathrm{~F}$} \\
\hline & Outside Jeddah & 9 & 100.0 & 0 & 0 & \\
\hline \multirow[t]{4}{*}{ Career } & Unemployed & 150 & 82.4 & 32 & 17.6 & \multirow{4}{*}{.676} \\
\hline & Retired & 15 & 88.2 & 2 & 11.8 & \\
\hline & Student & 32 & 86.5 & 5 & 13.5 & \\
\hline & Employed & 138 & 86.8 & 21 & 13.2 & \\
\hline \multirow[t]{4}{*}{ Family income (SAR) } & $\mathrm{Up}$ to $3 \mathrm{~K}$ & 59 & 73.8 & 21 & 26.3 & \multirow{4}{*}{$.011^{*}$} \\
\hline & $>3 \mathrm{~K}-5 \mathrm{~K}$ & 143 & 85.1 & 25 & 14.9 & \\
\hline & $>5 \mathrm{~K}-10 \mathrm{~K}$ & 97 & 91.5 & 9 & 8.5 & \\
\hline & $>10 \mathrm{~K}$ & 35 & 85.4 & 6 & 14.6 & \\
\hline
\end{tabular}

\section{Sociodemographic Factors Associated with OTC Analgesics Use}

The prevalence of OTC analgesic use was highest among illiterate (93.3\%) and highly educated participants (94.3\%), by comparison to other educational levels $(\mathrm{p}=0.000)$. Saudi nationals $(\mathrm{p}=0.000)$ and those with moderate family income $(>3 \mathrm{~K}-5 \mathrm{~K}$ SAR; $\mathrm{p}=0.011)$ had the highest prevalence of OTC analgesics use as compared with their counterparts (Table 4). There was no difference in the other sociodemographic factors.

Pattern and Knowledge of OTC Analgesic Usage by Gender, educational level and economic status

A higher proportion of males declared using OTC analgesics for mild pain (VAS $=0-3$ ) as compared to females ( $15.7 \%$ versus $8.2 \%$, respectively; $\mathrm{p}=0.028$ ). No statistically significant difference was observed otherwise regarding pattern of OTC analgesics used including drug used, supply source, frequency, duration of use, or health condition leading to OTC analgesics use. Differences were observed between the genders regarding knowledge sources; as well as behavior in case of non-efficacy of the OTC analgesic, where more females declared consulting the doctor and less declared shifting to another treatment, as compared to males (results not presented).

Paracetamol was likely to be more frequently used by participants with low educational level ( $\mathrm{p}=0.039)$; whereas ibuprofen was more frequently used by those with higher educational level, but the result was not statistically significant $(\mathrm{p}=0.103)$. Participants with high educational level had better knowledge about OTC analgesics side effects $(\mathrm{p}=0.000)$, and better awareness about the risk of hepatotoxicity $(\mathrm{p}=0.001)$, nephrotoxicity $(\mathrm{p}=0.002)$ and abdominal discomfort $(\mathrm{p}=0.026)$. No remarkable 


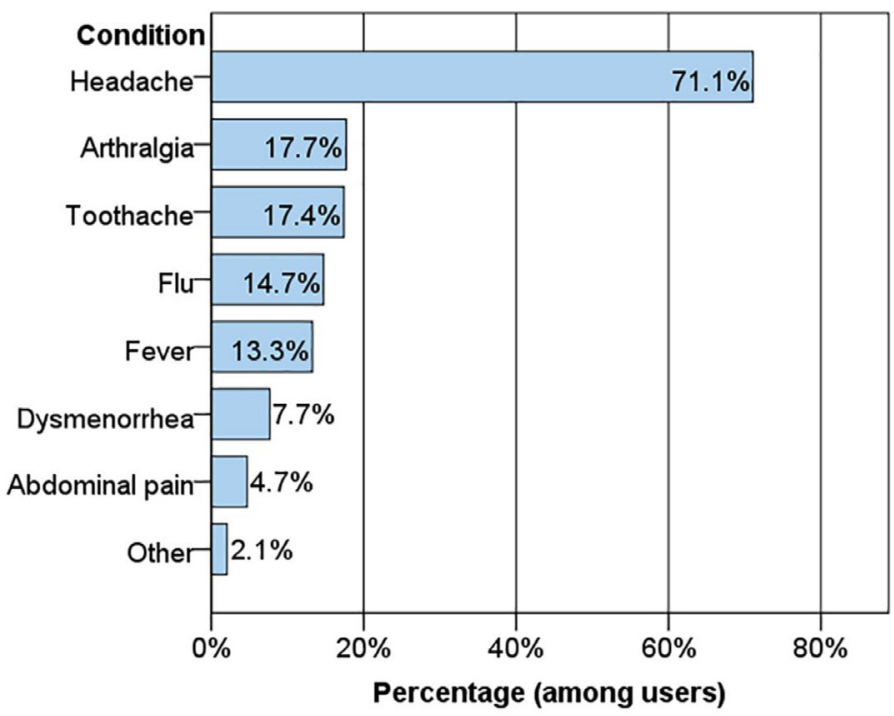

Figure 1 : Caption: Bars represent the percentage among OTC analgesics users who declared using OCT analgesics for the given condition. Other conditions include 1 case of biliary colic, 1 chest pain, 1 post-caesarean section, 1 post-delivery pain, 1 renal colic, 1 renal stones, 1 skin allergy. Reproduction size: at column width.

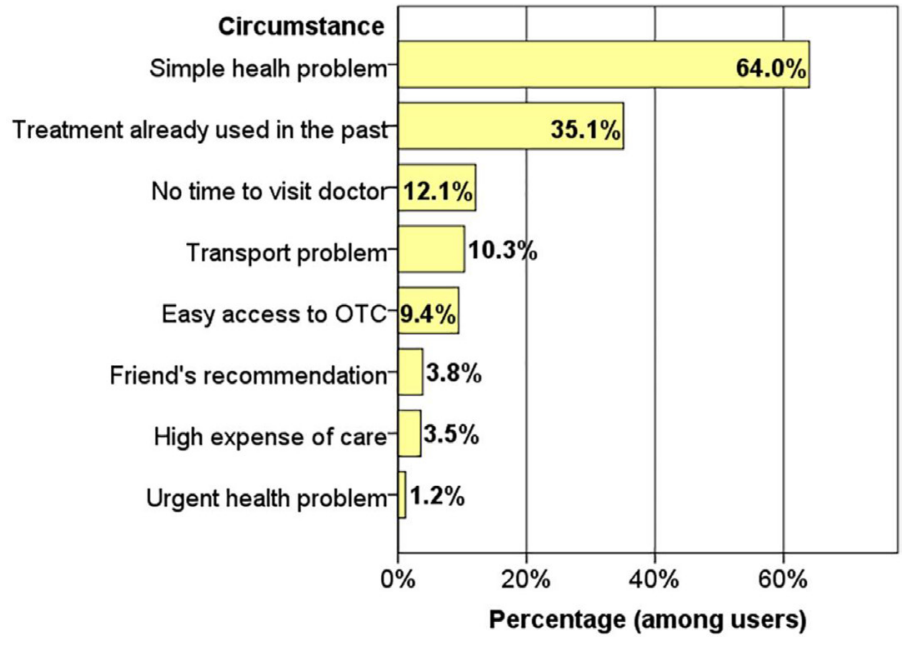

Figure 2 : Bars represent the percentage among OTC analgesics users who declared using OCT analgesics in the given circumstance.

Reproduction size: at column width.

correlations with educational level were otherwise observed (results not presented).

Users with moderate-to-high family income ( $>5 \mathrm{~K}-10 \mathrm{~K}$ SAR per month) reported more frequently to have a personal stock of OTC analgesics at home as compared to their counterparts $(\mathrm{p}=0.000)$. Those with high income ( $>10 \mathrm{~K}$ SAR per month) had better knowledge about the side effects of OTC analgesics ( $p=0.000)$, as well as about the related risk of hepatotoxicity ( $\mathrm{p}=0.001)$, nephrotoxicity $(\mathrm{p}=0.000)$, and abdominal discomfort $(\mathrm{p}=0.004)$ (results not presented).

\section{DISCUSSION}

The investigation outcomes of the current study showed that OTC analgesics was consumed by $84.8 \%$ of the participants, with headache being the leading health condition reported by $71.1 \%$ of users. Notable sociodemographic factors of OTC analgesics use included Saudi nationality, high and very low educational levels, and moderate-to-high family income.

The prevalence and pattern of OTC analgesics varies between countries because of variations in assessment method. In Norway, the prevalence of OTC analgesics use is reported as $47 \%$, which was lower than our finding; however, this was based on past month use. ${ }^{12}$ In Netherlands ${ }^{13}$ and Spain, ${ }^{14}$ the prevalence even lower, reported by up to $30 \%$ of the participants. However, the study from Netherlands only assessed usage of NSAIDs, while that from Spain investigated self-medication with analgesics, which may be different from OTC definition and may be over- or underestimating OTC analgesics.

In Saudi Arabia, paracetamol (Panadol) can be purchased in many convenience stores. Most of the studies reported paracetamol as being the most recurrent OTC drug, such as Saeed et al. who reported 35.7\% cases of self-medication with paracetamol among university students in Al-Qassim. ${ }^{15}$ and Khan et al. who demonstrated that paracetamol is the most requested drug among non-prescribed ones. ${ }^{16}$ In Norway, paracetamol is similarly the most frequently used OTC analgesic. ${ }^{12}$ All these findings correlate with the results from the current study. The availability and efficacy of OTC paracetamol not only makes it the most popular OTC analgesic, but also makes it frequently associated with risk of misuse or overuse, which may put forth the serious safety concerns.

Ibuprofen and diclofenac were the second most frequently used OTC analgesics, which was similar to the findings of Saeed et al. ${ }^{15}$ and Khan et al. $;^{16}$ however, both the authors investigated self-prescription and self-medication of all type of medicine and not only analgesics. In Netherlands, the prevalence of the use of NSAIDs was estimated to be $30 \%$ in the general population and $13 \%$ in individuals with high risk of NSAIDs adverse effects, ${ }^{13}$ which is considered to be high with regards of the related risks.

Saeed et al. reported headache as the major symptom leading to selfmedication among male university students (59.9\%), which is similar the present study results. ${ }^{15}$ The association of self-medication with headache, especially migraine, has long been considered as an issue, as it exposes to addiction and rebound headache syndrome, besides liver and gastrointestinal toxicity. ${ }^{17}$ Further, the use of OTC analgesics may delay the appropriate care and expose to treatment interactions..$^{18}$ On the other hand, it was observed that access to OTC analgesics combined with specific education program for patients with migraine improved their quality of life and enhanced migraine relief. ${ }^{19}$ These observations demonstrate that both safety and efficacy of OTC analgesics are conditioned by adequate patient's education and knowledge about the appropriate usage of these drugs.

Similar to present study results, A study from Riyadh reported that minor symptoms (54\%), time saving (40\%) and knowledge about the treatment required (40\%) were the major reasons for OTC drugs use. ${ }^{20}$ All these factors are dependent to consumer's own judgment and interpretation, and are greatly influenced by knowledge and attitude as well as previous experience with both the condition and the drug efficacy and safety. ${ }^{21,22}$ Further, there is a strong relationship between health beliefs and frequency of OTC medicine use as well as the choice of the drug. ${ }^{23}$

The present study results provide a picture of the level of awareness about the eventual harmfulness of these medicines, which may condition exposure to overuse and misuse. Less than half of users declared having knowledge about side effects and a minority were aware about nephrotoxic, hepatotoxic or allergic risks. The risk-benefit ratio of OTC analgesics is problematic from three major perspectives, which are: 1) the known drug health risks and side effects involving hepatic and gastrointestinal systems; 2) the frequent absence of medical supervision; and 3) the great availability of these drugs from a variety of channels..$^{24,25} \mathrm{We}$ 
conclude that the level of awareness about health risks is inadequate in the study population and should be more extensively investigated to determine the need for information and specific information to improve the risk-benefit ratio of OTC analgesics.

Similar to our findings, in Spain, analgesics self-medication was reported to be more practiced by younger, male, and highly educated population. ${ }^{14}$ In Australia, females and younger participants were more frequently reported as regular users, ${ }^{26}$ while no significant difference across genders and age were found in the present study. The high usage rate among highly educated and illiterate participants may results from opposed attitudes, which are knowledge about the drugs among highly educated and poor awareness among illiterate ones.

Analysis from this study stress the importance of safety in OTC analgesics use and its correlation with knowledge and awareness. Consequently, the physician-patient communication regarding OTC should be encouraged, as it has great contribution on patient's education and appropriate use of the OTC medicine. ${ }^{27}$

This study involves patient-reported side effects, which may not be an accurate method as this involves recall bias in addition to eventual difficulty to correlate the side effect with the OTC analgesic use. Other limitation is the self-assessment of knowledge about health risks related to misuse without verification of actual knowledge and understanding of the enumerated risks.

\section{CONCLUSION}

There is an alarming prevalence of OTC analgesics use among patients attending PHC centers in Jeddah, with paracetamol being the most frequently used drug and headache being the most frequent cause. Minor health problems and past use of the drug are the two major reasons of using OTC analgesics. This high usage rate is combined with inadequate level of awareness about the associated health risks, which raises several concerns about consumers' safety. Awareness and knowledge of OTC analgesics users should be further investigated to determine the need for information for specific or large-scale populations.

\section{CONFLICT OF INTEREST}

The authors declare no conflict of interest.

\section{REFERENCES}

1. Diener HC, Schneider R, Aicher B. Per-capita consumption of analgesics: a ninecountry survey over 20 years. J Headache Pain. 2008;9(4):225-31.

2. McGettigan P, Henry D. Use of Non-Steroidal Anti-Inflammatory Drugs That Elevate Cardiovascular Risk: An Examination of Sales and Essential Medicines Lists in Low-, Middle-, and High-Income Countries. PLoS Med. 2013;10(2):e1001-388.

3. Fendrick AM, Pan DE, Johnson GE. OTC analgesics and drug interactions: clinical implications. Osteopath Med Prim Care. 2008;2(1):2.

4. LeeWM. Acetaminophen toxicity: changing perceptions on a social/medical issue. Hepatology. 2007;46(4):966-70.

5. Budnitz DS, Lovegrove MC, Crosby AE. Emergency department visits for overdoses of acetaminophen-containing products. Am J Prev Med. 2011;40(6):585-92.
6. Nourjah P, Ahmad SR, Karwoski C, Willy M. Estimates of acetaminophen (paracetomal)-associated overdoses in the United States. Pharmacoepidemiol Drug Saf. 2006;15(6):398-405

7. Popa M. An Examination of Awareness of Over-the-Counter Nonsteroidal AntiInflammatory Drugs and Adverse Events. Walden University 2014.

8. Lanas A, Ferrandez A. Inappropriate prevention of NSAID-induced gastrointestinal events among long-term users in the elderly. Drugs Aging 2007;24(2):121-31.

9. Manthripragada AD, Zhou EH, Budnitz DS, Lovegrove MC, Willy ME. Characterization of acetaminophen overdose-related emergency department visits and hospitalizations in the United States. Pharmacoepidemiol Drug Saf 2011;20(8):819-26.

10. Pineles LL, Parente R. Using the theory of planned behavior to predict selfmedication with over-the-counter analgesics. J Health Psychol. 2013;18(12):1540-9.

11. Ibrahim NK, Alamoudi BM, Baamer WO, Al-Raddadi RM. Self-medication with analgesics among medical students and interns in King Abdulaziz University, Jeddah, Saudi Arabia. Pak J Med Sci. 2015;31(1):14-18.

12. Dale O, Borchgrevink PC, Fredheim OMS, Mahic M, Romundstad P, Skurtveit S. Prevalence of use of non-prescription analgesics in the Norwegian HUNT3 population: Impact of gender, age, exercise and prescription of opioids. BMC Public Health. 2015;15(1):461.

13. Koffeman AR, Valkhoff VE, Celik S, Jong GW t, Sturkenboom MC, Bindels PJ, et al. High-risk use of over-the-counter non-steroidal anti-inflammatory drugs: a population-based cross-sectional study. Br J Gen Pract. 2014;64(621):e191-8.

14. Carrasco-Garrido $P$, de Andrés AL, Barrera VH, Jiménez-Trujillo I, Fernandezde-las-Peñas C, Palacios-Ceña $\mathrm{D}$, et al. Predictive factors of self-medicated analgesic use in Spanish adults: a cross-sectional national study. BMC Pharmacol Toxicol. 2014;15(1):36

15. Saeed MS, Alkhoshaiban AS, AI-Worafi YMA, Long CM, others. Perception of self-medication among university students in Saudi Arabia. Arch Pharm Pract. 2014;5(4):149.

16. Khan TM, Ibrahim Y. A qualitative exploration of the non-prescription sale of drugs and incidence of adverse events in community pharmacy settings in the Eastern Province of the Kingdom of Saudi Arabia. Eur J Hosp Pharm Sci Pract. 2013;20:26-31.

17. Robinson RG. Pain relief for headaches. Is self-medication a problem? Can Fam Physician. College of Family Physicians of Canada. 1993;39:867.

18. Tonore TB, King DS, Noble SL. Do over-the-counter medications for migraine hinder the physician?. Curr Pain Headache Rep. 2002;6(2):162-7.

19. Burk CT, Gilderman A, Salas J, Berenbeim D, Nichol MB. The impact of an over-the-counter migraine medication program on quality of life. Headache. 2003;43(3):191-201

20. Aljadhey H, Assiri GA, Mahmoud MA, Al-Aqeel S, Murray M. Self-medication in Central Saudi Arabia: Community pharmacy consumers' perspectives. Saud Med J. 2015;36(3):328.

21. Hanna L-A, Hughes CM. Public's views on making decisions about over-thecounter medication and their attitudes towards evidence of effectiveness: A cross-sectional questionnaire study. Patient Educ Couns. 2011;83(3):345-51.

22. Berry D, Raynor T, Knapp P, Bersellini E. Over the counter medicines and the need for immediate action: a further evaluation of European Commission recommended wordings for communicating risk. Patient Educ Couns 2004 53(2):129-34

23. Häußinger C, Ruhl UE, Hach I. Health Beliefs and Over-the-Counter Product Use. Ann Pharmacother. 2009;43(6):1122-7.

24. Hersh EV, Moore PA, Ross GL. Over-the-counter analgesics and antipyretics: A critical assessment. Clin Ther. 2000;22(5):500-48.

25. Clarence M. Over-the-counter analgesics. Nurs Stand. 1990;5(10):24-7.

26. Stosic R, Dunagan F, Palmer H, Fowler T, Adams I. Responsible self-medication: perceived risks and benefits of over-the-counter analgesic use. Int $\mathrm{J}$ Pharm Pract. 2011;19(4):236-45.

27. Sleath $B$, Rubin $\mathrm{RH}$, Campbell W, Gwyther L, ClarkT. Physician-patient communication about over-the-counter medications. Soc Sci Med. 2001;53(3):357-69.

\footnotetext{
Article History: Submission Date : 27-09-2017 ; Revised Date : 09-11-2017; Acceptance Date : 25-11-2017.

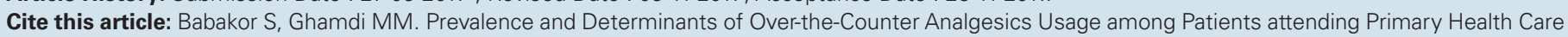
Centers in Jeddah, Saudi Arabia. J Young Pharm. 2018;10(1):91-7.
} 